\title{
SOBRE DELEUZE: PENSAR EN INFINITIVO ${ }^{1}$
}

\author{
Eduardo Forastieri-Braschi
}

Universidad de Puerto Rico, Río Piedras

\section{LA VELOCIDAD INFINITA}

Todavía trato de entender qué quiso decir Deleuze $(1994 b)^{2}$ por la velocidad infinita del pensamiento en uno de sus últimos títulos (¿Qué es la filosofía?). El modo interrogativo del título quizás tenga su respuesta en el modo verbal del presente de infinitivo. De hecho, ésta es la forma lingüística que Deleuze parece privilegiar cuando escribe sobre el tiempo: es un puro devenir. Devenir y pensar son correlativos, y la llamada velocidad infinita del pensamiento deviene en la forma

1 Leí una versión corta de este trabajo en noviembre de 1996 durante un homenaje a Deleuze, a un año después de su muerte, por la Sociedad de Filosofía Puertorriqueña.

2 Reconozco que este libro fue escrito en colaboración con Félix Guattari. Sin embargo, aquí sólo destaco lo que parece ser un tema particularizador del pensamiento deleuziano que es reconocible en obras de su única autoría como, por ejemplo, El pliegue, y La lógica del sentido. Para la fecha en que redacto sólo dispongo de la versión inglesa que aparece en la bibliografía (Deleuze, 1994a). Las traducciones al español son mías. 
lingüística del infinitivo cuando ésta expresa una misma temporalidad en su desinencia. La desinencia contrae y comprende las determinaciones de la extensión temporal. El pasado y el futuro se abrevian en un presente intensivo, infinitivo. De alguna manera, Deleuze, lo mismo que Epicuro, Lucrecio, Spinoza y Leibniz, considera que el pensamiento y el movimiento son el producto de una misma aceleración que comprime en una intensidad infinita el alcance de lo que se comprende en la extensión. De alguna manera, que es ella misma un manierismo filosófico, se integran la intensión y de la extensión del significado, es decir: el sentido (Sinn) y la referencia (Bedeutung) del modo fregeano; la comprensión profunda (Depth) y la anchura extensiva (Breadth) del modo peirceano. El movimiento en la extensión deviene, entonces, una intensión en el modo infinitivo, es decir: el de la intensidad de la velocidad infinita del pensamiento.

Pero todavía trato de entender. ¿Cómo conciliar la métrica del movimiento y las funciones de la velocidad con el pensamiento de la infinitud? Deleuze diseña su respuesta en el modelo geométrico de las coordenadas cartesianas de la extensión: el eje de equis (la variable independiente), el eje de ye (la variable dependiente), y la líneas paralelas, la abscisa y la ordenada, en las que el cálculo y el pensamiento correlacionan las coordenadas paralelas de lo mensurable y de lo inconmensurable. Es decir, que la respuesta a qué es la filosofía se diseña entre una coordenada abscisa que fija y apuntala las magnitudes de la extensión, y otra paralela ordenada que, sorpresivamente, se intensifica hasta el infinito desde la unidad puntual de su coordinación. En la ordenada intensiva, como la llama Deleuze, se adensan el concepto filosófico y la velocidad infinita del pensamiento, mientras que la abscisa sólo se limita a fijar los puntos de referencia entre las funciones y las derivadas del cálculo y de la ciencia.

Un concepto filosófico no fija constante alguna en las abscisas, sino que intensifica la infinitud en la magnitud de un orden sin vectores ni distancia. Por eso es una ordenada intensiva, y es a través de ella que el devenir acontece y altera las magnitudes de la extensión. Si por intensidad entendemos una magnitud física sin vectores que mide una energía (o una fuerza) por la unidad de la extensión a la que aquélla remite (lumen por unidad de área, métrica por unidad de tiempo), entonces un concepto filosófico comprende, en la ordenada de su coordinación, la velocidad de una intensisdad infinita para una extensión que no lo es. A su vez, la finitud de la extensión modifica la infinitud del concepto y de la filosofía. Y de esto último se trata; del modo: de cómo y de qué es pensar, y qué es la filosofía. 


\subsection{La intensidad expresa el modo y la magnitud infinitiva del concepto filosófico de la velocidad infinita}

La intensidad expresa, así, el modo y la magnitud infinitiva del concepto filosófico de la velocidad infinita del pensamiento. Deleuze corrobora esta interpretación cuando aclara que los conceptos son «las velocidades infinitas de movimientos finitos» (1994b: 36), y cuando consigna que éste es el problema del pensamiento, desde Epicuro hasta Spinoza, es decir: que el pensamiento requiere un «movimiento infinito o el movimiento de lo infinito» (1994b: 37); un movimiento desatado de las coordenadas de algún cálculo que lo detenga en el referente de una cantidad fija. Uno podría objetar que en el espacio abstracto de la física —en el llamado espacio Hilbert - tampoco existen fijezas para el tiempo. Sin embargo, en la ordenada intensiva del pensamiento, como la entiende Deleuze, no hay vectores que fijar porque el pensamiento no se dirige a la extensión como si de ésta dependiera su justificación, su validación, y su teleología. Tampoco hay regresos ni cómputos simétricos y reversibles que lo apuntalen ${ }^{3}$. El pensamiento sólo acontece, como en los verbos en infinitivo que sólo indican la modalidad de su predicamento de actividad; y ésta, solamente, cuando refiere al llamado acontecimiento de un puro devenir, sin inercia alguna que lo contenga, ni gradientes que lo desgasten.

\subsubsection{La ciencia detiene la velocidad infinita}

Deleuze (1994b: 118-122, 156) insiste en que la ciencia detiene la velocidad infinita. Las funciones del cálculo retardan el pensamiento cuando lo atrasan en el paralelo de la abscisa de unas velocidades conmensurables. El único valor delimitado entre las variables que una función mide no es más que el índice de su misma evanescencia cuando ésta ha sido arrancada de la velocidad infinita. Es decir: que el volumen evanescente que un ciclotrón le arranca en fracciones de

3 Esto supondría la adopción de los conceptos de la identidad y de su representación, que Deleuze sustituye por los conceptos de diferencia y de repetición. El concepto de una diferencia móvil, que continuamente se desvía en redobles y en doblajes, sustituye el de una identidad que habría de ser reconocida y representada. Deleuze (1968: 57) presume que se trata de una diferencia univoca, en el sentido de Escoto y de Spinoza. Es, además, virtualmente infinita. 
segundo al puro acontecer no es más que una demostración muy lenta, casi inmóvil, de su intensiva comprensión infinita. Y no sólo arranca$d a$, sino que el potencial del lumen y del fotón ha sido obligado a detenerse en una actualización cuantificada.

La filosofía, en cambio, mantiene la infinitud cuando la virtualidad se retiene con el pensamiento a través de la ordenada intensiva de un potencial inagotable. La virtualidad no se actualiza, sino que se substrae o se añade infinitesimalmente; sin que función alguna detenga las series de su convergencia, y que quizás sólo un mientras durativo y adverbial hubiera expresado perentoriamente, si otro mientras no viniera a arrebatarle su sombra con el devenir. Sólo el concepto filosófico (o el tropo de su infinitud acelerada) serían capaces de pensarlo y de expresarlo al vuelo. Lo sobrevuela (survole) sobre el llamado plano de la inmanencia; sin que trampas o transitividades lo remonten hacia alguna trascendencia explicativa. Insiste Deleuze (1994b: 47) en que tan pronto la trascendencia emerge o irrumpe en la inmanencia, entonces se detiene en seco la velocidad infinita. La ordenada intensiva, a través de la que se traslada el pensamiento, ni siquiera remite a los números de la transfinitud matemática, si es que ésta viniera a apoyar algún argumento a partir de alguna deducción trascendental sobre la infinitud. Ni Cantor, ni su célebre solución a la paradoja de los conjuntos infinitos, pueden detener la virtualidad denumerable de la cardinalidad aritmética, aunque lo intente. Por eso la solución cantoriana de una relación límite entre los conjuntos infinitos también se atasca ante el potencial de las virtualidades a las que sólo el pensamiento le puede otorgar consistencia. La consistencia del pensamiento no se hace cómplice de las funciones continuas del cálculo:

El cedazo filosófico, en tanto plano de la inmanencia que atraviesa el caos, escoge infinitos movimientos de pensamiento y se llena de conceptos formados a manera de consistentes partículas que se mueven tan rápidas como el pensamiento mismo. La ciencia se aproxima al caos de forma totalmente distinta, casi opuesta: renuncia a lo infinito, a la velocidad infinita, para alcanzar una referencia capaz de actualizar lo virtual. Por su retención de lo infinito, la filosofía le otorga consistencia a lo virtual mediante los conceptos; por su renuncia a lo infinito, la ciencia le asigna una referencia a lo virtual que lo actualiza mediante las funciones (Deleuze, 1994b: 118).

\section{EL INFINITISMO}

Ante esta encrucijada entre las funciones de la ciencia y los conceptos de la filosofía, Deleuze omite, sorpresivamente, las soluciones a las que ya él había remitido magistralmente en El pliegue cuando repasaba 
el infinitismo leibniciano ${ }^{4}$. Allí comentaba cómo las inflexiones de las series infinitas del cálculo infinitesimal se aproximan a un límite para ser implicadas —etimológicamente incluidas como plegados-en el predicado de una razón suficiente. Comentaba cómo, según Leibniz, todas las posibilidades infinitas se comprenden inclusivamente en el concepto, es decir: en el tropo de que todo predicado está incluido en el sujeto. Utilizo el término tropo adrede ya que todo El pliegue es un prolegómeno a Leibniz y al Barroco, o mejor, a Leibniz como un pensador del Barroco que entraña las implicaciones estéticas de toda una época. Dice, por ejemplo:

El concepto deviene un "concetto», o un ápice... los tratadistas del conceptismo... configuraron el mundo a manera de un cono que se revela y se le impone al mundo del Barroco... Los principales ejemplos de su filosofía [la de Leibniz] se muestran en la transformación del objeto perceptible en series de figuras o de aspectos sometidos a la ley de la continuidad; la asignación de los acontecimientos correspondientes a esos aspectos figurados, y que son inscritos en proposiciones; la predicación de estas proposiciones a un sujeto individual que contiene su concepto, y que se define como un ápice o un punto de vista, un principio de indiscernibles que asegura la interioridad del concepto (Deleuze, 1993: 126).

El principio leibniciano de la identidad de los indiscernibles resguarda en el sujeto la continuidad de las series infinitas, y la predicación de éstas entraña una lógica distinta.

\subsection{Leibniz y el Barroco}

Esta lógica, casi poética, tiene una consecutividad en la historia de las ideas en la que, aparentemente, también Leibniz se matriculó. Por ejemplo, el ensamblaje entre la dialéctica y la retórica que caracteriza a la poética del conceptismo tal como fue esbozada durante los siglos XVI y XVII, también asentó sus fundamentos lógicos en la predicación y en la categorización peripatética. Sin embargo, de conformidad con el nuevo estilo ciceroniano incoado por los humanistas y por los ramistas en el siglo XVI, los adjuntos del sujeto, como también los

4 Para la fecha de esta redacción sólo dispongo de la versión inglesa que aparece en la bibliografía (Deleuze, 1993). Las traducciones al español son mías. 
llamaría Gracián, habrían de adoptar al silogismo disyuntivo (locus de adjuncto) como la forma entimémica de una argumentación en la que la predicación habría de ser transformada en un concepto. Escribe Gracián:

Es el sujeto sobre quien se discurre y pondera [...] uno como centro, de quien reparte el discurso líneas de poderación y sutileza a las entidades que lo rodean; esto es, a los adjuntos que lo coronan, como son las causas, sus efectos, atributos, calidades, contingencias, circunstancias de tiempo, lugar, modo [...] (Gracián, 1960: 246).

Todos los tratadistas también coincidieron en que el concepto reunía en la agudeza las diferencias aspectuales que una predicación ingeniosa expresaba sobre un sujeto. De ahí que lo agudo representa un punto de convergencia entre las series de la pluriferencialidad al que concurren las figuraciones del lenguaje y del pensamiento. Quizás haya sido Sarbiewski el tratadista que más conscientemente elaboró esta acepción del concepto: acumen quodlibet mathematicum et materiale nihil aliud est nisi angulus quidem, seu duarum linearum concursus et coniunctio et in unum punctum coalescentium affinitas (1958: 10) ${ }^{5}$. La convergencia de los opuestos a una puntualidad afín, que también Nicolás de Cusa comparte con Leibniz y con Sarbiewski, es traducida por todos ellos al sujeto de las categorías de la predicación. Sobre todo Gracián y Tesauro, también jesuitas como Sarbiewski, tuercen verbalmente los predicables y los adjuntos del sujeto hacia el punto de su convergencia; a la correspondencia con que Gracián define el concepto en la Agudeza, y que otros jesuitas, Andrea Pozzo y Athanasius Kircher, afinan en la arquitectura y en las maquinas conceptuales del ilusionismo óptico. También aquí toda realidad es un sujeto cuyo predicado se aproxima en series infinitas al límite de su convergencia asíntota. Los indiscernibles de la predicación se acogen en el sujeto cuando convergen de forma parecida a la ecuación de una curva que permite alojar en sí infinitos puntos de intensidad infinitesimal. Se trata del llamado infinito sincategoremático que, sin embargo, Leibniz categoriza en los predicados de la infinitud substancial y teológica de la mónada, y que uno podría ver representado en la óptica del perspectivismo de las cúpulas del Barroco. La categoría de la substancia se

5 Le debo mi conocimiento y mi acceso a este texto a la gentileza de Robert Pring-Mill. 
adueña, entonces, de la predicación infinita y de la representación de lo infinito. Y a uno no le queda más remedio que pensarla a manera de un tropo, es decir: de pensar la infinitud con las figuras de la poesía como si fueran los iconos de la teología. Tanto la cúpula, como el ápice de la agudeza conceptista, remedan el espejismo del trompe l'oeil del Barroco: la perspectiva de lo finito que parece infinito incluye en la flexión de un puro acontecer visual el conjunto de todos los predicados que pretende representar. Como acontece con un verbo en el modo infinitivo, el espejo de tal intensidad para tanta extensión representada verbalmente en su desinencia sólo es conmensurable con las pretensiones infinitistas del pensamiento; como si éste fuera un tropo para la intensidad infinita, es decir: como si la velocidad infinita del pensamiento fuese un concepto barroco.

\title{
2.1.1. La mirada infinita (Nicolás de Cusa y el Barroco)
}

Y también como la mirada infinita de Nicolás de Cusa (imago omnia videntis). Escribe Alexandre Koyré sobre el cardenal:

\begin{abstract}
[Cada] cosa representa al universo de un modo distinto al de todas las demás, al contraer (contractio) la riqueza del universo de acuerdo con su propia individualidad única [...] El máximo absoluto e infinito, así como el mínimo absoluto e infinito, no pertenencen a la serie de lo grande y pequeño. Están fuera de ella y, por tanto, como audazmente concluye Nicolás de Cusa, coinciden [...]. Con todo, un cuerpo que se mueva con velocidad infinita [sic] a lo largo de una trayectoria circular estará siempre en el lugar de partida y, al mismo tiempo, estará siempre en otra parte; buena prueba de que el movimiento es un concepto relativo que abarca las oposiciones de rápido y lento [...] no hay mínimo ni máximo de movimiento, no existe ni el más lento ni el más rápido, y que el máximo absoluto de velocidad (velocidad infinita) así como su mínimo absoluto (lentitud infinita o reposo) están ambos fuera y, como hemos dicho, coinciden (1982:13-14).
\end{abstract}

Si bien esta coincidentia oppositorum, en la que el de Cusa abrevia la intensidad absoluta de la infinitud, permanece fuera de las series de la extensión, la comprensión de una mirada, también absoluta (oculus infinitus), reúne conceptualmente las magnitudes de la disparidad universal. También éstas son las premisas del conceptismo, y no es otro el supuesto que alentaba al jesuita Sarbiewski (1958: 10) a definir la agudeza como: Acutum est oratio continens affinitatem dissentanei et 
consentanei, seu dicti concors discordia vel discors concordia. Glosa Michel de Certeau:

\begin{abstract}
Uno también podría encontrar equivalentes para esta co-posibilidad de dos significados, de dos escrituras, o de dos narraciones que se oponen [...] cuando tuercen, invierten, y multiplican los senderos posibles de los que dependía el significado [...] crean una plurivalencia que es polisémica y, en el caso extremo, contradictoria en un texto que deviene una imagen [...] una combinación de movimientos reales y aparentes, tanto la oposición como la contradicción de dos prácticas visuales de lugar [...] trata de la mirada que genera rutas contradictorias; se enuncia en nombre de una conjunción (copulative), o acaso de una coincidencia en un centro que está en todas partes y en ninguna (1987: 16-25).
\end{abstract}

Esta visión de mundo todavía no había integrado la cosmología de Corpénico y, en efecto, se trataba de la esfera cuyo centro estaría en todas partes y su circunferencia en ninguna: permitiría los infinitos mundos posibles con que Giordano Bruno, y después Leibniz, habrían de contagiar las especulaciones cosmológicas y metafísicas. Asimismo, ésta es la misma premisa cosmológica del conceptismo, como han sugerido Mazzeo (1964: 55), Parker (1977: 32-33) y Molho (1990: 246). Por ejemplo, el cardenal advierte que lo multiple no existe a no ser que sea como un despliegue de la unidad que lo implica: quia non est multitudo nisi explicatio unitatis, sic de puncto quid est complicatio multitudinis pariformiter dicendum vides. Lo mismo que en los plegados leibnicianos de la infinitud, también la puntualidad del centro intensivo coincide con la infinita extensión de la esfera: circulum cuius centrum est ubique [...] sicut punctus in omni quanto ubique reperitur. Esta es la premisa mayor del ingenio (discretio); y es de su globalización conceptual (vis complicativa omnium notionalium complicationum) que depende la misma capacidad inventiva para pensar sobre todo lo que existe: et invenit disciplinas, scilicet arithmeticam, geometricam, musicam, et astronomicam, et illas in sua virtute complicari experitur [...] per homines inventae et explicatae [...] Unde et decem preadicamenta in eius vi notionali complicantur. Similiter et quinque universalia et quaequae logicalia [...] sine ipsis non potest discretio [...] (De Cusa, 1986: 100-106). Quizás no exista otro pasaje que exprese mejor cómo las premisas intelectuales de la búsqueda y de la idagación (inventio) habrían de transformar las condiciones infinitistas del universo, lo mismo que las posibilidades del ingenio y de la poesía. Resume Cassirer que «así como Dios genera todas las diferencias esenciales, asimismo el intelecto humano produce desde sí mismo 
todas las diferencias conceptuales, y es, por eso, la fuente de aquella armonía que siempre reconcilia los opuestos» (1935: 72).

\subsection{Los principios leibnizianos y el Barroco}

También Leibniz remite al tropo de un entimema que acorta distancias cuando implica velocidades distintas en el plegado de un concepto o de una mónada. También la condensada expresión de una elipsis, de un zeugma, de un quiasmo, o de un asíndeton, retienen las premisas elididas de alguna enálage transitiva entre los predicados del sujeto. Es decir, que también las secuencias y consecuencias de una serie se implican como entimemas y silogismos instantáneos en los que la identidad de sus indiscernibles ataja las premisas del movimiento y de la fuerza. Por ejemplo, la definición leibniziana de la fuerza logra que lo antecedente y lo consecuente, el futuro y el pasado, se contengan como una sola y apretada unidad: status ipse praesens, dum tendit ad sequentem seu sequentem praeinvolvit. Este es el tropo de una velocidad que también reúne la continuidad del movimiento con el predicado y con la razón de su suficiencia. $\mathrm{Si}$, de acuerdo a la definición estandardizada de fuerza, ésta es el producto de una masa por su aceleración, entonces decir masa, inercia o reacción, equivale a una atribución de esta propiedad física al pasado, mientras que la aceleración remite a un tiempo futuro que ya viene implicado (praeinvolvit) en la aceleración del presente (dum tendit) con la masa e inercia del pasado. La totalidad dinámica de la mónada se ve obligada, entonces, a contraerse en la identidad infinita de esa velocidad que también es infinita. Como si insinuara que la contractio de Nicolás de Cusa adumbró metafísicamente la llamada transformación de Hendrick Antoon Lorentz, según la cual una aceleración aumenta la densidad de una masa, mientras ésta se contrae en la dirección del movimiento; y mientras retrasa, con su energía, el tiempo de su duración. La paradoja de la simultaneidad del relativismo de Einstein también depende de esta torsión del espacio-tiempo, en la que la topología riemaniana arguye, casi poéticamente, los tropos y las transformaciones de un conceptismo geométrico universal. Parece que el margen de intersección entre la física y la metafísica del movimiento ya viene orientado a encontrarse o a perderse en la especulación infinitista. Así: los principios leibnizianos de la razón suficiente, de la identidad y de la con- 
tinuidad, son todos cómplices expresivos de la infinitud. Todos logran verbalmente implicar en un tropo una división descomunalmente abreviada: un numerador infinito compromete la mónada de su denominador en una misma expresión. Toda la multiplicidad divisible del universo se expresa y se espeja en la unidad infinita del denominador. Omnis in unum, dice. Multorum in uno expressio. Hasta la conocida fórmula leibniziana del movimiento es complice de este infinitismo de la mónada y de la teodicea: el producto de la masa por el cuadrado de la velocidad ( $\mathrm{mv} 2$ ) equivale a una fuerza capaz de contener los primitivos de la identidad en la secuencia de su movida, es decir: que la identidad retiene el pasado e involucra el futuro en la continuidad de una misma velocidad.

Me sospecho que es por esto que Deleuze omite a Leibniz en su repaso de ¿qué es la filosofía?, a pesar de su infinitismo. No obstante, también Spinoza, «el Cristo de los filósofos», según Deleuze (1994b: 60), comparte el análisis de lo infinito, justamente en la confluencia teológica a la que apuntabamos, aunque se aclara que la velocidad infinita del pensamiento sólo se da con el devenir, y esto: sólo en el plano de la inmanencia.

\section{SPINOZA}

\subsection{El modo infinito del pensamiento (sub specie aeternitatis), y el modo infinito de la extensión (facies totius universi)}

Tanto Spinoza, como Leibniz, proclaman en sus respectivos sistemas filosóficos el embalse categoremático de una substancia para contener la virtualidad caótica de la infinitud. La substancia garantiza la permanencia en el cambio, y sostiene un equilibrio infinito para un desequilibrio igualmente infinito. Así, el modo infinito del movimiento espinozista alcanza una cantidad constante que es la traza cinética para todo el universo (facies totius universi). A su vez, la infinitud condensada en la mónada leibniziana también espeja el universo. Ambos retienen, a su manera, el predicado y la categoría de la susbstancia de la teodicea. Porque de eso escribe Spinoza: de Deus sive 
natura, de una substancia en una teodicea distinta que ahora se atiene al plano de la naturaleza. Los modos infinitos del pensamiento y de la extensión remiten ahora a una sola susbstancia que reta las dualidades cartesianas. El pensamiento infinito y la extensión infinita son los atributos de esa única substancia infinita. Aunque Spinoza distingue entre la univocidad de Dios y el modo del pensamiento infinito, que es un pensar a la manera de lo eterno (sub specie aeternitatis), a esta manera no le queda más remedio que retener el manierismo de su infinitud en el entorno coextensivo de la naturaleza. Por eso es que la magnitud intensiva de tal pensamiento es infinita, como la velocidad que se contrae y se adensa en la ordenada de su conceptualización. Por eso Deleuze le otorga a Spinoza un sitial privilegiado en el plano inmanente de la filosofía que sólo tal pensamiento alcanza. Es decir: el tercer grado de conocimiento esbozado en el quinto libro de la Ética. «Allí alcanza velocidades increíbles, de contracciones tan centelleantes que uno sólo puede hablar de la música, de tornados, de viento y cuerdas» (Deleuze, 1994b: 48). Entonces el pensamiento alcanza la velocidad infinita: piensa todo el alcance del movimiento en la extensión.

\subsubsection{Natura naturans, Natura naturata: dos modos verbales para una misma susbstancia infinita}

¿Pero cómo expresar la consistencia inmanente y natural de las maneras infinitas de la extensión (conexio rerum) con las del pensamiento (conexio idearum) para tanta y tan alta infinitud? Spinoza mismo utilizaba los modos verbales del participio y del supino del latín. Una misma naturaleza se desdobla en la manera infinita del pensamiento en el participio, natura naturans, mientras que la manera infinita de la extensión se da en el supino de la natura naturata.

Sin embargo, esta es la misma encrucijada lingüística de la forma del infinitivo, que no llega a comprometerse con ninguna de las dos determinaciones: porque es un devenir puro. No se da como atributo de substancia alguna, ni existe, sino que más bien susbsiste o insiste - dice Deleuze- «con ese mínimo de ser que conviene a lo que no es una cosa... No son sustantivos ni adjetivos, sino verbos... No son presentes vivos, sino infinitivos: Aión ilimitado, —añade- devenir que se divide hasta el infinito en pasado y futuro, esquivando siempre el presente» (1994a: 28). 


\title{
4. EL INFINITISMO DE EPICURO Y DE LUCRECIO
}

Tales son, en efecto, los «simulacros» de la prolepsis epicúrea, como ya la había repasado cuidadosamente Deleuze en su Lógica del sentido: son trazas de superficies sensibles y falibles proyectadas desde su evanescencia veloz. Estoy convencido de que la noción inmanentista de la velocidad infinita, empleada por Deleuze consistentemente en ¿Qué es la filosofía?, fue incoada allí en un apéndice que trata del epicureísmo del poema de Lucrecio. A su vez, la noción había llegado con una cita de Epicuro tomada de la Carta a Herodoto en la que se plantea una correlación entre el mínimo de tiempo continuo y la dirección de los átomos. El átomo indivisible se corporiza de pensamientos mínimos durante la prolepsis mientras se anticipan (se adelantan) los simulacros instantáneos del devenir. Su percepción también es mínima. Por eso un simulacro expresa el más rápido, el más corto pensamiento. Escribe Epicuro que «el átomo se mueve tan aprisa como el pensamiento.» Y Deleuze glosa:

\begin{abstract}
El simulacro es, pues, insensible; sólo es sensible la imagen que porta la cualidad y que está hecha de la sucesión muy rápida, de la suma de muchos simulacros idénticos... Porque hay un mínimo de tiempo sensible como un mínimo de tiempo pensable, y un tiempo más pequeño que el mínimo de los dos casos... Y hablamos de un tiempo más pequeño que el mínimo de pensamiento pensable, en relación al clinamen como determinación del movimiento del átomo... (1994a: 275-77).
\end{abstract}

No olvidemos: el clinamen (la inclinación) es como la fuerza leibniziana en movimiento continuo, como el conato espinocista de persistencia constante a través del modo infinito de la extensión. Escribe Deleuze: «El clinamen es la determinación original de la dirección del movimiento del átomo... un diferencial de la materia, y por ello mismo un diferencial del pensamiento» (1994a: 270). En el poema de Lucrecio «incertus no significa indeterminado, sino inasignable; paulum, incerto tempore, intervallo minimo significan "en un tiempo más pequeño que el mínimo de tiempo continuo pensable"... (1994a: 270). Comenta Deleuze:

Podemos entonces responder a la cuestión del falso infinito... el clinamen inspira al pensamiento falsas concepciones de la libertad, los simulacros 
inspiran a la sensiblilidad un falso sentimiento de voluntad y de deseo. En virtud de su rapidez que los hace ser y actuar por debajo del mínimo sensible, los simulacros producen la ilusión de un falso infinito en las imágenes que forman, y hacen surgir la doble ilusión de una capacidad infinita de placeres y de una posibilidad infinita de tormentos... (1994a: 278).

\subsection{El verdadero infinito}

Deleuze concluye su repaso de Lucrecio con la distinción entre el verdadero y el falso infinito que son, justamente, la concepción inversa de los infinitos sincategoremáticos y categoremáticos leibnizianos, entre los que, a su vez, Lucrecio distingue a la filosofía de la religión. Sospecho, por eso, que la referencia tácita a Leibniz aquí y en otros textos trama la deuda de un cuestionamiento al que Deleuze responde:

Todavía somos todos leibnizianos, aunque los conciertos ya no dirigen más nuestro mundo o nuestro texto. Estamos descubriendo nuevas formas del plegado, afines a nuevos envolvimientos, pero todos nosotros permanecemos leibnicianos porque lo que siempre importa es el plegado, el despliegue, el repliegue (Deleuze, 1993: 137).

Como si dijera que también el plegado de Leibniz, lo mismo que un tropo, un entimema, o que el clinamen y los simulacros de Lucrecio, producen ilusiones con las imágenes que la aceleración confabula con la rapidez del pensamiento. Simulacros, fantasmas, espectros, imágenes: son los efectos que emergen de las derivadas del tiempo mínimo y de la ligereza entre los átomos y el pensamiento. Se da, no obstante, una gradación entre las velocidades de lo pensable y de lo sensible, y a la inversa. La cuestión es dirimir cómo el mínimo de tiempo pensable entre los átomos y el pensamiento, o cómo el mínimo del tiempo sensible que se apresura con el clinamen entre los simulacros y las imágenes, gradúan un deslinde entre la verdadera y la falsa infinitud (Deleuze, 1994a: 276).

Se preguntaba, entonces, Deleuze, en el apéndice de 1969, la misma pregunta que veintidós años después le serviría de título y de legado a eso que Foucault habría de proclamar; que: «quizás algún día este siglo habrá de conocerse como deleuciano» (Foucault, 1977: 
165). Se preguntaba Deleuze a propósito del texto de Lucrecio hace veintisiete años: ""para qué sirve la filosofía?" - y continuaba- es preciso responder: ¿qué otro interés tiene que no sea... denunciar todas las fuerzas que tienen necesidad del mito...?» (1994a: 278-279). Deleuze retiene la misma pregunta titular y la misma respuesta de entonces. Transaba desde entonces un convenio entre el arte, la ciencia, y la filosofía; todos comparten positivamente un devenir porvenir. «Lo múltiple - escribía - en tanto que múltiple es objeto de afirmación, como lo diverso en tanto que diverso es objeto de gozo... La pura positividad de lo finito es el objeto de los sentidos; la positividad del verdadero infinito, es el objeto del pensamiento» (Deleuze, 1994a: 280).

Sin embargo, en su más reciente respuesta al mismo cuestionamiento, Deleuze remite a las premisas bilógicas de una inmersión acelerada al caos por los vórtices sinápticos del potencial eléctrico del cerebro, que de alguna manera también recuerda el potencial material del clinamen epicúreo. Desde allí habría que extraer la sombra de un pensamiento por venir. En efecto, la positividad del verdadero infinito es el objeto del pensamiento, y el cuerpo integra esta esperanza al estilo de Epicuro y de Spinoza. Sin embargo, un cuerpo en deterioro es incapaz de sostener la velocidad infinita del pensamiento, ni de «medir simultaneamente la presencia compartida del concepto con todos sus componentes intensivos» (1994b: 214). Casi concesivamente, el pensamiento se apoya en un reticulado de planos complejos que agrupa las funciones de la ciencia con las sensaciones del arte y con los conceptos de la filosofía: los unos son indecidibles (funciones, sensaciones, conceptos), y los otros indiscernibles (ciencia, arte, filosofía) ${ }^{6}$. Deleuze advierte que los diversos planos (filosofía, arte, ciencia) se agrupan como si compartiesen una misma sombra que constantemente los persigue (1994b: 218). A pesar de su convenio entre estos indiscernibles, la filosofía tiene que salvar la infinitud, no sólo de las sombras que emergen con la velocidad, sus trampas y sus tristezas trascendentes, sino también de las figuraciones del cálculo y de las funciones cuantificadas de la ciencia.

6 Diríase que la identidad de estos indiscernibles, y su continuidad, se sustentan en las premisas leibnicianas de las series infinitas y en la razón suficiente de su posibilidad. Y esto, a pesar del supuesto deleuciano que postula que es la diferencia, y no la identidad, la que predica la univocidad múltiple de un ser que se repite y se desdobla incesantemente. A su vez, esto sólo se entiende, si es que el atributo de lo indecidible es, como el modo verbal infinitivo, la desinencia unívoca de una pluralidad que contrae todos los tiempos en una sola diferencialidad. 


\section{EI PRINCIPIO DE ACCIÓN MÍNIMA}

\subsection{La acción mínima y la acción a distancia}

Epicuro y Lucrecio presagiaron, con el intervalo mínimo infinitesimal más pequeño que el tiempo continuo pensable, la quietud con que la inercia también se resiste a todo movimiento acelerado. No obstante, parece que tal movimiento obtiene una solución física en la constante de Planck $(\mathrm{E}=\mathrm{h} / \mathrm{v})$. Parece que también el cuanto de acción se atiene al principio del menor esfuerzo de Maupertuis, y que la física (y la linguiística) también articulan el dinamismo de la energía (y del sintagma) de conformidad con las proporciones de su economía: que los plegados, las implicaciones, las complicaciones y las explicaciones se compasan de conformidad con el conjunto de su extensión conmesurable. Es decir: que todo movimiento articula su economía entre los extremos de la acción mínima y de la acción a distancia, que Newton intentó resolver con sus leyes, pero que todavía se plantea como el dilema fundamental de la teoría física. Parece que la resistencia y el movimiento se implican mutuamente en la entraña misma de la energía (y de las expresiones) a la medida constante de su finitud.

¿Cómo alentar, entonces, la velocidad infinita del pensamiento si las constantes mínimas del cuanto de acción y de la velocidad de la luz restañan el movimiento y la distancia a la medida de la economía de su finitud? Parece que la acción y el esfuerzo mínimos de una inversión proporcional entre magnitudes finitas indican que a mayor distancia, real o infinitesimal, menor es el margen que tiene el pensamiento para adaptarse a las funciones de un cálculo conmensurable. Por ejemplo, el intento de la física cuántica por determinar sus valores sólo es compensado por el aumento de esfuerzo con que los aceleradores de partículas acortan su aproximación al mínimo que pretenden fijar; y esto: al precio del principio de la incertidumbre de Heisenberg. Lo mismo sucede con otras economías finitas, como la del lenguaje; que mientras más esforzado es el sintagma de una articulación, menos frecuente es su instancia en el discurso, pero mayor la incertidumbre para el hallazgo de su sorpresa, de su tropo imprevisto: de su concepto. La estadística linguística aplicada a la semántica postula, por ejemplo, que las expresiones más improbables significan más cuando no obedecen la cadena markoviana en la que la mayor probabilidad de una expresión debería venir condicionada por la expresiones que le 
anteceden en el sintagma. No hay, pues, una economía rentable que, con un mínimo esfuerzo, logre alcanzar y reunir en la suscinta unidad de una magnitud o de una expresión, la energía coextensiva de las fuerzas físicas o la intensidad de los significados de las palabras. Resume Giovanna Madonia:

En el cálculo relativo de la energía gastada para producir un fonema, un monema, un sintagma, una frase, no hay que olvidar nunca que inercia de la memoria e inercia articulatoria son dos fuerzas que se oponen, y que la energía gastada en el acto de habla es la suma de ambos factores: realizar una economía sobre el eje sintagmático significa gastar menos energía articulatoria, realizar una economía sobre el eje de paradigmático significa gastar menos energía de la memoria (1979: 71).

Por lo tanto, realizar una economía entre ambos ejes a manera de la proyección de la memoria sobre la articulación en el tiempo del acto de habla, viene a ser lo mismo que la proyección de aquel principio de equivalencia de Jakobson (1960: 358) que resume toda actividad lingüística en la llamada función poética. La función poética (que no es lo mismo que una función matemática) epitomiza toda actividad lingüística cuando tuerce la redundancia del tiempo lineal, de la energía y de las palabras, en la economía de una proporción que es invertida cuando se realiza el habla. El principio de equivalencia contraviene, así, el de la linealidad saussuriana: abrevia en una elección articulada las relaciones entre los significados con que se distribuye la energía y el tiempo de las palabras. Por eso la poesía, y quizás también un concepto filosófico, economizan el significado de las palabras cuando actualizan el contenido de una equivalencia en un tropo que abrevia la redundancia de una extensión expresiva sobrecargada de ruido y temporalizada de olvido.

La inversión proporcional con que el lenguaje y el pensamiento economizan la energía, y que la inercia de la memoria retiene en contra de la redundancia y del tiempo, remite a la analogía de una misma solución propuesta por Newton (y que, posiblemente, Jakobson remedó en su esquema linguístico) para resolver la economía de la acción a distancia entre masas. Por un lado, se da la inercia y su resistencia al movimiento que la apegan a la acción mínima y al menor esfuerzo, y por otro lado, su acción también se da entre las otras masas del movimiento gravitatorio. Una y otra inercias lingüísticas, la de la memoria y la de la articulación, que parecen remedar una acción (fuerza) que es proporcional al producto de sus masas e inversamente proporcional al 
cuadrado de la distancia entre ambas (si es que nos atenemos al principio de la estricta equivalencia de Newton), también tienen que resolver y salvar la distancia que las implica. Ernst Mach, por ejemplo, sotuvo un principio de inercia general en el que cada cuerpo del universo correlacionaría combinadamente con todos los demás en las escalas estelares de un traslado inmensamente complicado y grandioso. No habría una invariación rotativa, sino un torbellino de variaciones correlacionadas globalmente. Por suerte especulativa, ni la poesía ni el concepto filosófico tienen que dirimir el cálculo con que Einstein intentó integrar la inercia general de Mach, al menos en teoría, a la acción mínima y a la acción a distancia para la economía de su llamado principio cosmológico. El principio de inercia general de Mach viene a ser, entonces, una acción a distancia que se pierde entre las magnitudes de lo sublime o de lo insoluble para las funciones del cálculo y de la ciencia.

Parece que la acción mínima y el esfuerzo mínimo son cómplices de toda inercia. Traman un principio económico del que dependen las inversiones proporcionales, las torsiones y los tropos que intentan salvar toda distancia: que a mayor distancia del significado poético haya menos probabilidades y menos frecuencia, también aumenta, por otro lado, la magnitud sorpresiva del concepto inesperado que invierte las propensidades del cálculo y de sus funciones continuas, si es que adviene, de pronto, algún significado nuevo a lo que ya es sabido, es decir: el adviento y la aventura de la llamada cantidad de información. Quizás ésta sea la medida del significado en su extensión, como enseñan la semiótica de Lotman y la estética de Upenski. ¿Pero lo es, acaso, de la intesidad de su significado, como la ordenada intensiva de Deleuze, la mirada infinita del de Cusa, o los conceptos infinitistas de los filósofos del Barroco?

Todavía no estoy seguro si la velocidad infinita del pensamiento es un tropo invertido a la medida del la función poética y de su economía, o si se trata de un concepto filosófico que las rebasa. Posiblemente tenga que reunirlos en la sombra de un reticulado de planos inmanentes (¿filosofía, arte, ciencia?) que le arrebatamos a la infinitud con el cuerpo, como sugiere Deleuze; y no saber de qué se trata. Qué es la filosofía, todavía es el cuestionamiento. El naturalismo de Spinoza, o el de Lucrecio (con la recuperación de la acción mínima y la finitud de su economía) todavía convocan más preguntas y más respuestas que las del infinitivo de un mero devenir que acontece como solía responder Deleuze. Quizás tengamos que recuperar la forma lingüística de 
otro pensar gerundivo, es decir, casi un infinitivo. Quizás, al estilo de Spinoza, nos convenga el pensamiento de una natura naturandam por venir.

\section{Referencias bibliográficas}

CASSIRER, E. (1935). Individuo e cosmo nella filosofía del Rinascimento, F. Federici (trad.). Firenze: La Nuova Italia.

De Certeau, M. (1987). «The Gaze Nicholas of Cusa», C. Porter (trad.). Diacritics 17, 2-38.

De CuSA, N. (1986). De Ludo globi, P. Moffitt Watts (ed.). New York: Abaris Books.

DELEUZE, G. (1968). Différence et répétition. Paris: P.U.F.

- (1993). The Fold, T. Conley (trad.). Minneapolis: University of Minnesota Press.

- (1994a). Lógica del sentido, M. Morey (trad.). Barcelona: Paidós.

Deleuze, G. y F. Guattari (1994b). What is Philosophy, H. Tomlison y G. Burchell (trads.). New York: Columbia University Press.

Foucault, M. (1977). «Theatrum Philosophicum», D. F. Bouchard y S. Simon (trad.). En Language, Counter-Memory, Practice, D. F. Bouchard (ed.). Ithaca: Cornell University Press.

Gracián, B. (1960). Obras Completas, A. del Hoyo (ed.). Madrid: Aguilar.

JAKoBSON, R. (1960). «Closing Statement: Linguistics and Poetics». En Style in Language, T. A. Sebeok (ed.), 350-377. New York: Wiley.

KoYré, A. (1979). Del mundo cerrado al universo infinito, C. Solís Santos (trad.). México: Siglo Veintiuno Editores.

MAdONIA, G. (1979). «Economía», C. Manzano (trad.). En La linguística. Guía alfabética, A. Martinet (ed.). Barcelona: Anagrama.

MAZzeO, J. A. (1964). Renaissance and Seventeenth-Century Studies. New York: Columbia Univesity Press.

MolHo, M. (1990). «Tientos para una teoría semántica gongorina». MLN 105, 244-259.

PARKER, A.A. (1977). «Introduction». En Luis de Góngora. Polyphemus and Galatea. A Study in the Interpretation of a Baroque Poem, G.F. Cunningham (trad.). Austin: University of Texas Press.

SarbiEwski, M.K. (1958). Praecepta Poetica, S. Skimina (ed.). Krakow: Wroclaw. 